(3)

Volume 22, 2019

\title{
INTERNATIONAL STANDARD OF TRANSDISCIPLINARY EDUCATION AND TRANSDISCIPLINARY COMPETENCE
}

Vladimir Mokiy

Institute of Transdisciplinary Technologies, vmokiy@yandex.ru Nalchik, Russian Federation

\section{ABSTRACT}

Aim/Purpose

The year 2020 marks the 50th anniversary of the first official definition of the term "transdisciplinarity." This paper focuses on a critical analysis of the development of modern transdisciplinarity since its inception.

Background

The article presents two main directions for the development of transdisciplinarity. It also shows its identification features, strengths, and weaknesses, as well as the significant role transdisciplinarity plays in science and education.

Methodology

The methodology employed in this article is a content analysis of resolutions of international forums as well as articles on transdisciplinarity published from 1970 to 2019.

Contribution

For one reason or the other, several of these authors did not quote the opinions of the original authors of transdisciplinarity. The subsequent use of those articles by other authors thus posed some ambiguities about the place and role of transdisciplinarity in science and education. The advent of e-databases has made it possible to access the original forum articles. This further made it possible to refine the original content of the term "transdisciplinarity" and to trace its development without mixing it with vague opinions. Based on these findings, the perception of transdisciplinarity as a marginal trend in science and education could be eliminated.

Findings

This paper shows how modern transdisciplinarity is developing into two main directions: transdisciplinarity in science as well as transdisciplinarity in education. These orientations have individual goals and objectives. The transdisciplinarity of scientific research helps to complete the transformation of the potential for interdisciplinary interaction and the integration of disciplines. Whereas, in education, transdisciplinarity (meta-discipline) is about developing an international standard for transdisciplinary education and also

Accepting Editor Eli Cohen | Received: October 29, 2019| Revised: November 26, December 3, December 10, December 19, 2019 | Accepted: December 21, 2019.

Cite as: Mokiy, V. (2019). International standard of transdisciplinary education and transdisciplinary competence. Informing Science: the International Journal of an Emerging Transdiscipline, 22, 73-90. https://doi.org/10.28945/4480

(CC BY-NC 4.0) This article is licensed to you under a Creative Commons Attribution-NonCommercial 4.0 International License. When you copy and redistribute this paper in full or in part, you need to provide proper attribution to it to ensure that others can later locate this work (and to ensure that others do not accuse you of plagiarism). You may (and we encourage you to) adapt, remix, transform, and build upon the material for any non-commercial purposes. This license does not permit you to use this material for commercial purposes. 
Recommendations If it takes one woman nine months to produce a child; putting nine women for Practitioners together will not produce a child in one month. Therefore, the effectiveness of solving a multifactorial problem will not depend on the number of specialists of many scientific disciplines. It will depend on a systems transdisciplinary methodology that is capable of unifying and consolidating disciplinary knowledge on a case-by-case basis.

Recommendations Transdisciplinary research involves the interaction of people with disciplinary for Researchers knowledge plus a degree of scientific outlook. Since disciplinary knowledge domains remain in their disciplinary boxes, it is, therefore, advisable to generalize disciplinary knowledge rather than force them to interact. This is the basis for proposing the systems transdisciplinary approach — which provides a methodology for unifying and generalizing disciplinary knowledge.

Impact on Society From a historical perspective, society has always created conditions for the consistent development of people's outlook. In this process, a special role is played by the process of formation and development of scientific outlook. The development of a scientific outlook is directly linked to the reforms of higher education. These reforms focus on the relationship between disciplinary, interdisciplinary, and transdisciplinary knowledge within the university structure. Thus, the information, organizational, and material support of the society for the transition of universities to the transdisciplinary training of disciplinary specialists will help to form the level of scientific outlook. Through this, it will be possible to solve multifactorial problems of modern society.

Future Research As the research shows, the organizers of modern international forums do not take into account the division of transdisciplinarity development trends. To increase the effectiveness and significance of such forums, it is necessary to return to the practice of organizing special international forums on the transdisciplinarity of science and that of education.

Keywords transdisciplinarity, transdisciplinary research, systems transdisciplinary approach, higher education, unicentrism, Russian school of transdisciplinarity

\section{INTRODUCTION}

A great deal has been written about transdisciplinarity that is not well understood, particularly by those who are not familiar with new scientific directions. Transdisciplinarity is the highest form of integration and generalization of knowledge about the world. Therefore, it can be argued that transdisciplinarity is a way of expanding the horizon of human and scientific worldview, allowing you to see and describe the world in all its diversity. Based on this sense, transdisciplinarity is a term that serves diverse meanings.

The first meaning of transdisciplinarity as a "declaration" is establishing equal rights of famous or less famous scientists, big or small scientific disciplines, cultures, and religions in the exploration of the ambient world. In this case, transdisciplinarity plays the role of a "writ of protection" for any particular point of view and does not interfere with knowledge of individual scientific disciplines (Nicolescu, 1994). 
Secondly, transdisciplinarity represents the high level of education and the many-sidedness and universality of the knowledge of some persons.

The third meaning of transdisciplinarity is associated with the rules of exploration of the ambient world. Transdisciplinarity is suggested to be actualized if the problem is being treated on several levels simultaneously, for example, on both physical and mental levels or global and local levels (Mello, 2001).

Fourthly, transdisciplinarity is perceived as the principle for the organization of scientific knowledge. It offers a wide range of opportunities for the interaction of diverse disciplines to solve complex problems of nature and society. It should be noted that this fourth meaning officially allows scientists to leave the boundaries of their disciplines without fears of accusation for dilettantism (Nicolescu, 1987).

Like every field in science, the mathematical form of transdisciplinarity began to develop as well. According to a school of scientists who considered their studies as part of this form of transdisciplinarity, complex objects or the combination of their physical, biological, technical, informational, and social intricacies (cenosises) have the same invariant structure. Thus, they could be described with one mathematical apparatus of hyperbolical (non-Gaussian) distributions. Today, there is a significant number of objects in different fields that present the power-mode (hyperbolical) law of distribution. This circumstance let mathematicians to suggest a paradox hypothesis that evolution is based not on the majority and diversity of species but the law of their distribution within a corresponding area (Fufaev, 2006).

In recent years, there have been studies proposing three forms of transdisciplinarity: theoretical, phenomenological, and experimental. According to this school of thought, theoretical transdisciplinarity covered scientific activities related to the research of transdisciplinary methodologies. Then, phenomenological transdisciplinarity represented a transdisciplinary model that can combine theoretical principles with observed experimental data leading to foreseen results. Also, the experimental transdisciplinarity presented a form that employs a determined procedure for implementing experiments. It is considered that the simultaneous examination of theoretical, phenomenological (intuitive), and experimental transdisciplinarity can be implemented within one, non-dogmatic treated transdisciplinary philosophy, theory, and practice (Brenner, 2014).

The literature on transdisciplinarity indicates a wide spread of the classification of directions (types) of transdisciplinarity suggested by Belgian researcher, E. H. Judge (1994). The classification has five types of transdisciplinarity.

Transdisciplinarity- 0 uses the illustrative potential of metaphors and figurative language. Therefore, it is commonly and effectively used in domains of human spiritual activity such as philosophy, art, religion, and those scientific disciplines that are interested in some "borderline" fields connected with these spiritual activities.

Transdisciplinarity-1 is based on the formal interconnection of scientific monodisciplines. Remarkably, specialists of different scientific disciplines demonstrate tolerance and trust to each other's knowledge in solving a complex problem. Therefore, transdisciplinarity-1 is often used by numerous expert groups that approve its affiliation to interdisciplinarity and multidisciplinarity.

Transdisciplinarity- 2 has a closer inner connection with the personal experience of the researcher, including meditation. Supporters of Transdisciplinarity- 2 consider that researching the physical essence of the object, without examination of its mental (spiritual) development, does not provide a complete presentation.

Transdisciplinarity-3 uses general metaphors that have fundamental educational meaning. In a sense, the term "system" is an example of a universal metaphor. The following expressions can serve as an example of such metaphors, "The Universe is the largest system ever known to science;" "An atom is 
a system of elementary particles." This leads to the assumption that transdisciplinarity-3 contributed to the establishment of systems approach, its conception, terminology, and methodology.

Transdisciplinarity-4 is established as an independent scientific discipline (meta-discipline) that supports the generalization of disciplinary knowledge. This meta-discipline has all the requirements that allow it to be presented and used in the higher education system and for the solution of complex multifactorial problems of nature and society.

There are grounds to talk about transdisciplinarity as a way of integrating the knowledge of science, philosophy, and religion as well as a new way of obtaining knowledge (Nowotny, Scott, \& Gibbons, 2001).

It is likely that new meanings, forms and types of transdisciplinarity will appear in the future.

The purpose of this article is to provide a contextual analysis of the resolutions of major scientific forums and articles in authoritative journals on the topic of transdisciplinarity published from 1970 to 2019. This paper observes that modern researchers in their articles and books prefer to interpret rather than fully quote the opinions of their colleagues expressed in these materials. This interpretation allows them to build their understanding of transdisciplinarity, to give its definition, to designate its types, forms, as well as to propose new classifications. However, it is known that processes have their main stages. These stages characterize the degree of maturity of the process, its approach to completion, and the obtaining of results. This article attempts to identify these stages as well as the periods of the process of development of transdisciplinarity in only two areas - science and higher education. The obtained knowledge about the process of development of transdisciplinarity will allow for effective managing of the process of forming of a new transdisciplinary meta-discipline in the future.

\section{SEMINAR ON INTERDISCIPLINARITY IN UNIVERSITIES, 1970}

The first international forum to articulate and address issues of inter-disciplinary collaboration, including transdisciplinarity, is Seminar on Interdisciplinarity in Universities, Paris, September $7^{\text {th }}-12^{\text {th }}$, 1970. This seminar was organized by the Centre for Educational Research and Innovation (CERI), which was a part of the Organization for Economic Cooperation and Development (OECD) in collaboration with the French Ministry of Education at the University of Nice, France.

The seminar organizers pointed out that the lack of clear terminology that could be used to distinguish between the institutional structures of universities and the curricula they offered was a source of confusion for the experts' discussions on interdisciplinary interactions. Therefore, at the beginning of the seminar, G. Michaud formed a set of working terms. Among these terms was transdisciplinarity. Transdisciplinary entails establishing a common system of axioms for a set of disciplines (G. Berger, 1972). It should be noted that this definition of transdisciplinarity laid the foundation for its high potential (future prospects) as a transdisciplinary meta-discipline. Within the framework of the seminar, the content of this definition of transdisciplinarity was supported and developed by the Austrian astrophysicist, E. Jantsch, but in their own way interpreted by Swiss psychologist, J. Piaget, and French mathematician, A. Liehnerowicz.

\section{J. PIAGET AND E. JANTSCH: TWO AREAS OF TRANSDISCIPLINARITY}

Leo Apostel, a member of the editorial board of Seminar on Interdisciplinarity in Universities, placed a special emphasis on the concepts of transdisciplinarity proposed by Jantsch and Piaget. According to Leo Apostel (1972):

We could not hope to show all interdisciplinary conceptual systems, all 'interlanguages', but we could make a selection. The contributions of Jean Piaget, Andre Lichncrowiez, and Erich Jantsch have been selected. (p. 79) 
We decided upon the following presentation:

I. Transdisciplinarity from the point of systems approach (view of the general value system of the total society): Erich Jantsch.

II. Transdisciplinarity from the point of view of research itself.

a) Mathematics as a universal language: Andre Liehnerowicz.

b) Theory of the psychodynamics of knowledge as a universal language; Jean Piaget (p. 81).

In March 1970, during the preparation of the proceedings for the Symposium, E. Jantsch published an article. In this article, he writes:

In response to various pressures for change arising from the present situation, the university will have to adopt a new purpose which may be recognized as a means of increasing the capability of society for continuous self-renewal. Ultimately, the entire education/innovation system may become coordinated as a multilevel multigoal hierarchical system through a transdisciplinary approach, implying generalized axiomatics and mutual enhancement of disciplinary epistemology. (Jantsch, 1970)

In September 1970, in his report at the Symposium, E. Jantsch clarifies his point:

The ultimate degree of coordination in the education/innovation system, finally, which may be called transdisciplinarity, would not only depend on a common axiomatic derived from coordination towards an 'overall system purpose' but also on the mutual enhancement of epistemologies in certain areas. With transdisciplinarity, the whole education/innovation system would be coordinated as a multi-level, multi-goal system, embracing a multitude of coordinated interdisciplinary two-level systems, which, of course, will be modified in the transdisciplinary framework. Transdisciplinarity - the coordination of all disciplines and interdisciplines in the education/innovation system on the basis of a generalized axiomatic and an emerging epistemological pattern. A systems approach as it is proposed in this paper would consider science, education, and innovation, above all, as general instances of purposeful human activity, whose dynamic interactions have come to exert a dominant influence on the development of society and its environment. Knowledge would be viewed here as a way of doing, a certain way of management of affairs. (Jantsch, 1972, pp. 105-106)

Piaget was more interested in the prospect of natural integration (improvement of relations) of disciplines, but not in their external form of coordination. Therefore, in his understanding, transdisciplinarity is the highest form of such integration. Thus, transdisciplinarity was mentioned by Piaget only in the last section of his extensive report. He said:

We may hope to see a higher stage succeeding the stage of interdisciplinary relationships. This would be 'transdisciplinarity', which would not only cover interactions or reciprocities between specialized research projects but would place these relationships within a total system without any firm boundaries between disciplines. (Piaget, 1972, p. 138)

Having gotten acquainted with the understanding of J. Piaget's transdisciplinarity, E. Jantsch (1972) said:

I think the most essential feature of both Professor Piaget's paper and my own lies in the consideration of inter- and transdisciplinarity as organizational principles, actively modifying disciplinary concepts, principles, boundaries and interfaces. For Professor Piaget, they achieve disciplinary co-operation at the same hierarchical level; for me, purpose-oriented coordination from a higher level. I am not altogether sure, though, that Professor Piaget's concept does not also involve some hidden ad hoc coordination from a higher level, through a 
common axiomatics. In both approaches, inter and transdisciplinarity act as inductive principles, express the human systems perception for Professor Piaget, and human systems creation for me. (p. 100)

So, the research of the primary materials of Seminar on Interdisciplinarity in Universities, Paris, September $7^{\text {th }}-12^{\text {th }}, 1970$, allows us to draw the following conclusion. Since 1970 , transdisciplinarity has developed in two main directions. The first is transdisciplinarity for science (transdisciplinarity of scientific research), to which Piaget referred. The second is transdisciplinarity for education (transdisciplinary metadiscipline), to which Jantsch has referred.

\section{TRANSDISCIPLINARITY FOR SCIENCE: TRANSDISCIPLINARITY OF SCIENTIFIC RESEARCH}

The term "transdisciplinarity for science" is used to refer to the natural predisposition of disciplinary knowledge to synthesize within a specific transdisciplinary study. However, the synthesis of knowledge does not imply and does not welcome the unification of knowledge itself. It does not welcome their reduction to ideas about the object of any one science. Such a convergence would destroy the principle of the importance and equality of each discipline. Therefore, the transdisciplinarity for science stimulates the development of the entire spectrum of interdisciplinary interactions in scientific research. Also, E. Morin (1999) wrote this about it:

Factually, it is the multidisciplinary and transdisciplinary complexes that work and play a fruitful role in the history of science; it is worth remembering the key concepts that are involved here, namely, cooperation, more precisely, interconnection or interrelation, or, more precisely, joint project. (p. 136)

The relationship between disciplinary approaches within the framework of a joint project is based on the principle of tolerance. This is evident in the outcome document of the first world congress of transdisciplinarity (Convento de Arrábida, November 6, 1994). The Charter of Transdisciplinarity says:

Article 3: Transdisciplinarity complements disciplinary approaches. It occasions the emergence of new data and new interactions from out of the encounter between disciplines. It offers us a new vision of nature and reality. Transdisciplinarity does not strive for mastery of several disciplines but aims to open all disciplines to that which they share and to that which lies beyond them.

Article 7: Transdisciplinarity constitutes neither a new religion, nor a new philosophy, nor a new metaphysics, nor a science of sciences. (Nicolescu, 1994)

B. Nicolescu, who was one of the authors of The Charter of Transdisciplinarity, criticized the reasoning of Piaget about transdisciplinarity. Nicolescu (2006) said:

In his contribution, Piaget gives the following description of transdisciplinarity: 'Finally, we hope to see it succeeding to the stage of interdisciplinary relations at a superior stage, which should be "transdisciplinary", i.e., which will not be limited to recognize the interactions and or reciprocities between the specialized researches, but which will locate these links inside a total system without stable boundaries between the disciplines.' This description is vague, but has the merit of pointing to a new space of knowledge 'without stable boundaries between the disciplines.' However, the idea of a 'total system' opens the trap of transforming transdisciplinarity in a super- or hyperdiscipline, a kind of 'science of sciences.' In other words, the description of Piaget leads to a closed system, in contradiction with his requirement of the instability of boundaries between disciplines. The key point here is the fact that 
Piaget retained only the meanings "across" and "between" of the Latin prefix trans, eliminating the meaning 'beyond.' Thus, transdisciplinarity is just a new but 'superior' stage of interdisciplinarity. (p. 142)

This attitude to transdisciplinarity can be explained by the widespread of the principles of theoretical and methodological pluralism and epistemological anarchism of the American-Austrian philosopher and science methodologist, P. Feyerabend. At the time, this philosopher argued: "Despite the importance of the method for science, it cannot be reduced to a set of rigid, unchanging and obligatory principles of scientific activity. It is unacceptable when any method is declared 'only true' and universal" (Feyerabend, 1986).

At modern rates of development of the human consciousness, science, and technology, it was possible to expect that comprehension of bases of transdisciplinarity and the description of its identification signs should be completed. However, in the direction of "transdisciplinarity for science," this did not happen. Transdisciplinarity researchers believe:

Despite its increasing popularity, transdisciplinarity is still far from been academically established, and current funding practices do not effectively support it at universities and research institutions. One reason for this deficit is that a universally accepted definition for transdisciplinarity is still not available. Consequently, quality standards that equally guide researchers, program managers and donors are widely lacking. Therefore, a rhetorical mainstreaming of transdisciplinarity prevails which risks marginalizing those who seriously take the integrative efforts creative collaboration requires. (Jahn, Bergmann, \& Keil, 2012)

Similar conclusions were reached by the participants of the International Transdisciplinarity Conference (Joining forces for change, Gothenburg, Sweden, 10-13 September, 2019) (International Transdisciplinarity Conference, 2019). Bergmann and Jahn (2019) said:

Today, transdisciplinary research is regarded as standard where the issues of change, transformation, and sustainable development are concerned - even if there are different ideas about what transdisciplinarity is and how it should be practiced in research. Recent years have seen the development of new approaches and framings in an attempt to strengthen the effectiveness of research in societal transformations. One consequence has been a weakening of the theoretical foundations of transdisciplinary research. Research that draws on the transdisciplinary research mode tends to transition from a scientific approach to the mere application of participatory processes. (p. 161)

Kasa and C. Pohl (2019) in their report noted several problems. They said:

Co-creation is most needed when we face complex challenges where there is no known best practice. When it is obvious that no party has the answer or even the ability to find the answer by themselves, transdisciplinarity is required. Transdisciplinarity is also required when it takes a multitude of perspectives and experiences to jointly explore and find ways forward. In these cases, the answers lie in diversity and at the same time diversity in itself is a big challenge and a potential pitfall. Over the last decade, several collections evolved that suggest methods and tools for co-creation, such as the Team Science Toolkit, the Tools for Integration and Implementation Sciences, and td-net's toolbox for co-producing knowledge. These collections showcase the diversity and plurality of tools and methods to be used in transdisciplinary projects. The practical use of methods is flexible and situational and requires knowhow and skills in facilitation. Facilitation is a means to balance the different interests embedded in a transdisciplinary project. The level of facilitation needed is dependent on the complexity of the task, and it is associated with the backgrounds of the participants in the project. Facilitating is the skill required to create scaffolding, a structure, and a safe container where enough chaos can be brought in for co-creation to happen and new things to be born. 
Transdisciplinary Education and Transdisciplinary Competence

There is not a single method for this; what is needed is rather an ability to identify and combine the methods that best supports the work at hand. (p. 106)

Lotrecchiano and Misra (2018) categorically stated the problems of interaction between specialists in transdisciplinary teams. They said:

One category of systemic complexity pertains to the barriers to TD integration arising from interpersonal interactions in TD team-based contexts, called interactive systemic complexities. Interactive systemic challenges to TD integration include perceived inequitable contributions to the project, unbalanced problem ownership, discontinuous participation, fear of failure, variability in communication types and skills, overall lack of participant satisfaction with the project processes and outcomes, among others. Structural systemic complexities, on the other hand, are barriers to TD integration that arise from characteristics inherent to the makeup of teams. These include differences in foundational training among team members, diverse and changing career paths, geographic dispersion, a lack of awareness of the breadth and complexity of the problem, perceived insufficient legitimacy of a team to solve the problem, conflicting methodological standards, conflicting epistemological and ontological orientations, and differing levels of transdisciplinary orientation among team members. (pp. 5253)

The views of the authors of the cited articles and reports have revealed the main reason for the ineffective development of the direction - transdisciplinarity for science. Social psychologists and Nobel Prize winners in psychology (2000) J. Kruger and D. Dunning, both colleagues of Piaget's, have proved the limitation of the direction laid down by him. These scientists have stated:

People tend to hold overly favorable views of their abilities in many social and intellectual domains. This overestimation occurs, in part, because people who are unskilled in these domains suffer a dual burden: Not only do these people reach erroneous conclusions and make unfortunate choices, but their incompetence robs them of the metacognitive ability to realize it. Without the self-awareness of metacognition, people cannot objectively evaluate their competence or incompetence. (Kruger \& Dunning, 1999)

The apotheosis to the direction of "transdisciplinarity for science" is the statement of E. Morin (2005): "The method does not give a priori path, but the laying of this path. The method is formed in the process of scientific research and as experience is accumulated, it forms a posteriori" (p. 19). Therefore, in modern transdisciplinary research, the main aspect shifts to the management of transdisciplinary team specialists and optimization of their interaction. It is management efficiency and optimization of the interaction of specialists that contributes to the formation of unique methods. As mentioned above, the practical use of such methods is flexible and ad hoc, and requires know-how and facilitation skills, i.e., to find the necessary level of simplification in the interaction of professionals. In this case, the result of the work of the transdisciplinary team is evaluated as a result of using this method. However, it is not an assessing the correct or erroneous solution to a multifactorial problem, it is not an assessing the moral responsibility of the team members for this solution. From the point of view of this method, this problem has only such a solution or no solution at all.

\section{THE LIMITATION TO TEACH TRANSDISCIPLINARITY FOR SCIENCE}

From the information above, in the direction of "transdisciplinarity for science", the creation of a textbook is a problem. The authors of a few books, which can be accepted as a textbook, are forced to write in the preface to their books:

This book is not intended as a self-contained canon; rather it should be regarded as a foundation to be built upon and enriched. For transdisciplinary research, because of its diverse references to the social world, it is open to a wide variety of concepts, methods, and criteria. (Bergmann, Jahn, Knobloch, Krohn, Pohl, \& Schramm, 2012, p.15) 
Scientific articles are not always practically useful to scientists, practitioners, teachers, and students. In 2013, a group of scientists (Brandt et al., 2013) reported the results of bibliometric content analysis of available "full articles" in the Scopus database, published from January 1970 to August 2011:

Content analysis shows 236 transdisciplinary papers were identified and subsequently classified as follows: 33 studies emphasized the importance of transdisciplinarity only in the conclusion (call for transdisciplinarity); 71 papers discussed transdisciplinary approaches throughout the text (argumentation); 28 papers developed methods for undertaking transdisciplinary research (methods) or transdisciplinary frameworks within which methods could be applied (frameworks) yet did not apply them; 104 papers were identified as real-world case studies (application) following a transdisciplinary approach. (p. 3)

The results of this analysis allowed the authors to draw the following conclusion:

While transdisciplinary research is growing, there is no common glossary, no focused communication platform, and no commonly shared research framework. Transdisciplinary research utilizes a broad, but not clearly defined, set of methods for knowledge production. While the intensity of practitioner involvement varied within the case studies analyzed, very few realized empowerment. Based on our review of transdisciplinary case study papers we conclude that transdisciplinary research must be clearly framed, including the use of a common terminology and the development of a broad suite of appropriate methods. (Brandt et al., 2013, p. 1)

It should be noted that these subjective and objective shortcomings of the first direction of development of transdisciplinarity for science (transdisciplinarity of scientific research) are absent in the second direction of development of transdisciplinarity for education (meta-discipline).

\section{TRANSDISCIPLINARITY FOR EDUCATION: TRANSDISCIPLINARY META-DISCIPLINE}

Effective development of the direction "Transdisciplinarity for education" was hampered by at least three main factors. First, it is the proponents of a mono-disciplinary structure of higher education who saw no reason to break down the boundaries of disciplinary boxes. Secondly, it is the editorial policy of reputable scientific journals, which gives preference to the publication of monodisciplinary and interdisciplinary scientists and practitioners. For example, there is yet no high-ranking Journal of Transdisciplinary Research Practice which would provide scope for publishing broadly on transdisciplinary research methods and promote interaction across a wide range of transdisciplinary researchers (Kueffer, Hadorn, Bammer, Kerkhoff, \& Pohl, 2007). The role of the third factor is played by the founders and admirers of some kinds of transdisciplinarity. The special opinion of these scientists until 1998 was fixed in the final documents of major scientific forums devoted to the use of transdisciplinarity in higher education. For example, Article 3 of the Declaration of the symposium "Science and the Boundaries of Knowledge: The Prologue of our Cultural Past," organized by UNESCO in collaboration with the Giorgio Cini Foundation (Venice, 3-7, March 1986), says:

While not wishing to attempt a global approach, nor to establish a closed system of thought, nor to invent a new Utopia, we recognize the pressing need for truly transdisciplinary research through a dynamic exchange between the natural sciences, the social sciences, art and tradition. (Akyeampong, Margalit, d'Ambrosio, Nakamura, Berger, \& Nicolescu, 1986)

In the Declaration of the Congress "Science and Tradition: Transdisciplinary Perspectives, Openings Towards the 21st Century" (Paris, UNESCO, 2-6 December 1991), it was said: Article 4: Transdisciplinarity does not seek to construct any syncretism (unification) between science and tradition. Article 6: By definition, there can be no transdisciplinary experts, but only researchers driven by an attitude of transdisciplinarity (R. Berger, Cazenave, Juarroz, Freitas, \& Nicolescu, 1991). In the working document of the International Congress "Which university for tomorrow? Towards a transdisciplinary evolution of the University" (Locarno, Switzerland, 30 April - 2 May 1997), it was written: 
As transdisciplinarity is not a new discipline, there is no question of creating new "transdisciplinary" chairs. On the other hand, it is highly desirable to set up transdisciplinary research workshops in a few pilot universities, which are true centres of excellence. The purpose of these workshops will be to promote the transdisciplinary spirit through concrete proposals concerning the transversal coordination of programmes and the internal institutional measures to be taken in order to promote transdisciplinary interaction between teachers and teachers. (Gobeil, \& Nicolescu, 1997)

Thus, the authors of these important international documents suggest that university rectors develop a transdisciplinary spirit within the framework of transdisciplinary research workshops, instead of forming a scientific transdisciplinary worldview within the framework of standard transdisciplinary chairs!

Ten years later, B. Nicolescu will confirm his understanding of transdisciplinarity. In an interview with R. Volkmann he says:

Returning to your previous question I am saying now that transdisciplinarity is not a metatheory. It's not a theory at all. It's both science and art. In fact, it is neither science nor art. It's a new knowledge you cannot reduce to old knowledge. (Volckmann, 2007, p. 84)

B. Nicolescu has great achievements in the formation and development of transdisciplinarity for science (transdisciplinarity of scientific research). This is probably why he does not take into account the fact that both old knowledge and new knowledge find their meaning and identification signs only within the framework of classical disciplines and / or meta-disciplines. On this occasion, L. Lattuca (2001) writes:

Disciplinarity has been largely asserted through structuralist accounts of knowledge production and defined as frameworks for "understanding and interpreting information and experience[s], for judging the validity and adequacy of solutions to problems by defining what is acceptable, appropriate, and/or useful. Implicit in this model is a role for the individual, who interprets, judges, etc., and a role for the disciplinary community, which maintains disciplinary boundaries. The structuralist definition of disciplinarity is largely the dominant ideology in universities as the desired organizing principle, and while efforts to disrupt this are present, disciplinarity stands as the stronghold organization system. (p. 24)

And yet the active development of interdisciplinary interaction at the end of the 20th century, caused by the need to solve the multifactorial problems of modern society, has changed the attitude towards the idea of the formation of transdisciplinary science (meta-discipline). This attitude was recorded in the final documents of international forums, which had an impact on the development of higher education in the 21 st century.

The first of these forums was a symposium "Transdisciplinarity. Stimulating synergies, integrating knowledge" which took place in Royaumont Abbey (France) in May 1998. The final document of this forum reads:

Transdisciplinarity is conceived as 'meta-methodology': a transdisciplinary approach that takes as its object precisely the different methodologies of the various disciplines, in order to 'transform' and to 'transcend' them. Transcending and transforming are seen here not as vague procedures to replace disciplinary methodologies with global, fuzzy, problem-solving techniques. On the contrary, they are conceived as rigorous processes of abstraction, inasmuch as a transdisciplinary approach, intended to tackle global problems, needs to be general. (Kim, 1998, p. 38)

The second forum was "World Conference: Higher Education in the Twenty-First Century: Vision and Action" was held at the UNESCO Headquarters, Paris, October 1998. The declaration of this conference says: 
Article 5(a): (a) The advancement of knowledge through research is an essential function of all systems of higher education, which should promote postgraduate studies. Innovation, interdisciplinarity and transdisciplinarity should be promoted and reinforced in programmes with long-term orientations on social and cultural aims and needs. Article 6(b) Higher education should reinforce its role of service to society, especially its activities aimed at eliminating poverty, intolerance, violence, illiteracy, hunger, environmental degradation, and disease, mainly through an interdisciplinary and transdisciplinary approach in the analysis of problems and issues. ("World Declaration," 1998)

In the United States in 2013, representatives of 23 leading U.S. universities, including the Massachusetts Institute of Technology (MIT) and Harvard University, initiated and developed the report "ARISE 2" (Advancing Research in Science and Engineering). The authors of the report stated:

The committee concludes that the objective is to achieve transdisciplinarity and to integrate fields beyond the levels of the multidisciplinary. Here, multiple disciplines operate simultaneously, or the interdisciplinary occupies the space between disciplines. For the term "transdisciplinary," the committee sees leveraging of existing concepts and approaches from multiple disciplines to derive new concepts and approaches. This in turn results to new ways of achieving and utilizing understanding. Hence, transdisciplinary implies an integration-driven emergence of new disciplines, not just ad hoc collaborations. (American Academy of Arts and Sciences, 2013, p. 14)

Thus, the participants of these prestigious forums unequivocally spoke out for the transdisciplinarity that can be seamlessly integrated into the traditional educational process and university structure. In this context, "transdisciplinarity for education" should be a separate discipline-meta-discipline. Such discipline should form competence in the field of management of complex processes, solution of multifactor problems of nature and society. Such a meta-discipline should be taught in universities using special textbooks and teaching aids. With the training in this meta-discipline, students should be able to pass their exams and receive well-deserved grades. And finally, students must learn to see the world in all its diversity, and also to know and use in their practical activities mechanisms that preserve the unity of a diverse world.

Therefore, transdisciplinarity, as a meta-discipline, is a way of broadening the scientific worldview, which is based on unification and generalization of disciplinary knowledge within the framework of systemic thinking. This version of transdisciplinarity was developed within the framework of the Russian School of Transdisciplinarity and associated with systems transdisciplinary approach (Rimondi \& Veronese, 2018).

Transdisciplinarity as a meta-discipline has basic attributes: a meta-theory and a meta-narrative.

Meta-theory is a description of the general representation about the fundamental features of the world order and the forms of their manifestation, which form the basis of the entire system of human knowledge about the surrounding reality. The set of initial worldview reference points and the main philosophical categories within the framework of the meta-theory of transdisciplinarity undergoes certain intellectual processing - rethinking, ordering, and generalization. The purpose of the meta-theory of transdisciplinarity is to create a picture of the one and only world. Disciplinary (local) pictures of the world, in this case, are considered as abstract models of certain areas (fragments) of the one and only world. As a result, the meta-theory of transdisciplinarity appears to be a scheme that defines the way and context of building scientific models of the researched areas (fragments) of reality. Such a scheme, because of its abstract nature, provides a transdisciplinary interpretation of the results of modeling the fragments of reality within the framework of different disciplinary and interdisciplinary approaches.

Meta-narrative is a universal system of notions, signs, symbols, and models, which aims to create a single type of description of objects and the presentation of interrelated events in the picture of the one and only world. This meta-narrative summarizes the knowledge and languages of scientific disciplines, as well as cultural and semantic discourses (areas of interaction). Meta-narrative is formed in 
the process of philosophical rethinking of general concepts and categories (space, time, information, system), which are necessary and sufficient to describe the picture of the one and only world (Mokiy \& Lukianova, 2016).

This understanding of meta-theory and the meta-narrative of transdisciplinarity as meta-discipline has always attracted the support of philosophers. Aristotle also said: "The object of all knowledge is the common. Knowledge of everything has the one who has the most knowledge of the common" (Aristotle, 335-323 BCE). According to E. Laszlo:

In the case of transdisciplinary unification of the evolutionary variety, a specific worldviewfactor intervenes. In adopting an evolutionary framework, we no longer look at phenomena as things or objects that are to be described as they are. Instead, we describe phenomena in terms of how they come to be. (Laszlo, 1995)

\section{SYSTEMS TRANSDISCIPLINARY APPROACH: GENERAL PROVISIONS}

The systems transdisciplinary approach is based on the philosophic principles of unicentrism. In a broad sense, unicentrism is a position in philosophy and in science that is based on the problem of the correlation between the unity and its fragments. This position is based on the isomorphism (similarity) of the general order of the structure of fragments of space, the attributes of information, and the periods of time that are able to describe the one and only world. Any objects at all levels of the reality of the one and only world are its natural elements and fragments. Therefore, the main condition for the existence of the one and only world is the existence of a general order in it (transdisciplinary system). As the name implies, it follows that this order must manifest itself everywhere: in every element and fragment of this world and in every interaction of these elements and fragments at every level of reality. As a result, the same order should ensure the achievement of activity goals and results of all these elements and fragments. In addition, it should synchronize these goals and results. For this reason, the one and only world is a One Orderly Medium (Mokiy, 2019b).

Therefore, the order determining unity is not revealed in the course of systems transdisciplinary research of a complex object. It is not formed subjectively as it is done in other types of systems approach. It is postulated through systems transdisciplinary models of the spatial, informational, and temporal units of order. The model of spatial unit of order provides ground for the physical and/or logical object boundaries and the nature of relations between elements within these boundaries. The model of an informational unit of order provides ground for the necessary and sufficient amount of information on the object. The model of a temporal unit of order shows the organization of converting the internal potency of object from the original volume to the results that will be used in the subsequent processes of its conversion (Mokiy, 2019a).

The world in the form of vertical functional assembly and the system in the form of the general order, which makes the condition for the unity of this assembly, are close to the vision of L. Bertalanffy with respect to the general systems theory. L. Bertalanffy (1968) wrote:

A unitary conception of the world may be based, not upon the possibly futile and certainly farfetched hope finally to reduce all levels of reality to the level of physics, but rather on the isomorphy of laws in different fields. Speaking in "material" language, it means that the world, i.e., the total of observable events, shows structural uniformities, manifesting themselves by isomorphic traces of order in the different levels or realms. (pp. 48-49) 
Thus within the framework of transdisciplinary meta-discipline, disciplinary knowledge were able to maintain their borders in the process of their unification (see Figure 1).

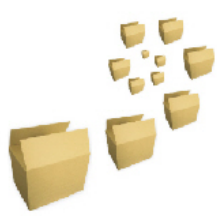

Monodisciplinarity

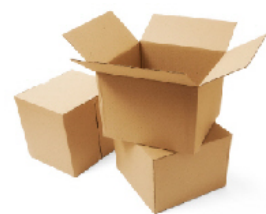

Interdisciplinarity

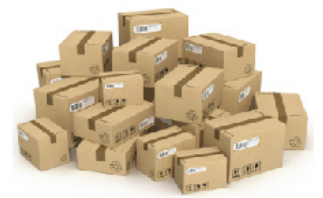

Multidisciplinarity

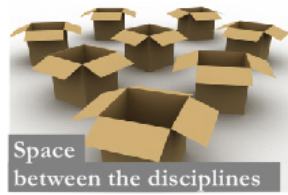

Transdisciplinarity for science

(Transdisciplinarity of scientific research)

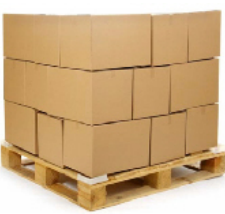

Transdisciplinarity for education

(Transdisciplinary meta-discipline)

Figure 1. Placement of "disciplinary boxes" in various forms of integration and generalization of monodisciplinary knowledge

\section{STAGES OF RECOGNITION OF TRANSDISCIPLINARITY AS A META- DISCIPLINE}

Endowing transdisciplinarity with the traditional attributes of scientific discipline - philosophical substantiation, concept, methodology, technological solutions, it is possible to organically integrate it into the existing classification of scientific directions and scientific approaches. In turn, the creation of textbooks, manuals, training programs, as well as the organization of special training and retraining of teachers will allow us to organically integrate this transdisciplinary meta-discipline into the educational process of universities. Thus, this will make it possible to change the attitude towards the transdisciplinarity of academic researchers and practitioners as a marginal experience not integrated into the structure of universities. Furthermore, it will also help to complete the evolutionary stage of higher education.

By combining the events described in this paper with the systems transdisciplinary model of the temporary unit of order, it was possible to determine the important development parameters of the transdisciplinary metadiscipline (see Figure 2).

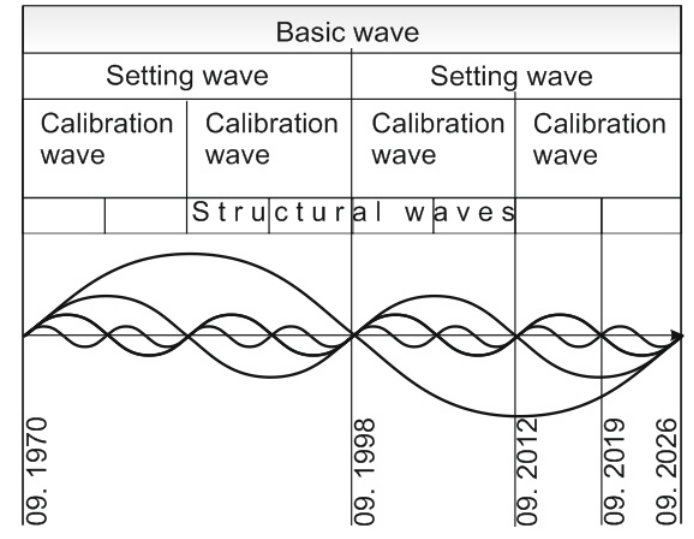

Figure 2. Systems transdisciplinary model for the development of transdisciplinarity of education

For a proper understanding of the model, it is necessary to give short explanations. A Basic wave is a depiction of complete duration of development of objects or functional ensemble of objects. A Setting wave is a depiction of duration of inevitable stages of development of object or functional ensemble of objects. A Calibration wave is a depiction of periods, which differentiates logical combina- 
tion of basic stages (moments) of development of object or functional ensemble of objects. A Structural wave is a depiction of periods, which differentiates logical combination of current events of development of object or functional ensemble of objects. Basic wave and Setting waves are carriers of a hard development program. Calibration waves and Structural waves are carriers of a soft development program (Mokiy \& Lukianova, 2019). Within the framework of a soft development program, current events that are associated with real-life are formed and take place. Within the framework of a rigid development program, significant events are formed and occur that synchronize the goals and results of the events of the soft programs. Seminar on Interdisciplinarity in Universities, Paris, September $7^{\text {th }}-12^{\text {th }}, 1970$ is an event that lays down the potency, goals, and meanings of all four types of waves - the hard and soft programs of development of transdisciplinarity for education (meta-discipline), the meaning of which was laid down by G. Michaud and E. Jantsch.

The symposium "Transdisciplinarity: Stimulating synergies, integrating knowledge" took place in Royaumont Abbey (France) in May 1998 - it was no ordinary event. This event characterized the end of the first rigid development program (Setting wave). Therefore, it was proclaimed at this symposium that transdisciplinarity is conceived as "meta-methodology". This definition of transdisciplinarity has given meaning to the second Setting wave (hard program). In addition, it occurred in October 1998, when the World conference was held in France - Higher Education in the Twenty-First Century: Vision and Action. At the conference, the need to use transdisciplinarity in the training of university students was officially announced.

September 2012 is the critical point for the second wave of the hard program. Thus, it was in September 2012 that the initiative and editorial groups in the United States entered the final phase of the work on preparation for the publication of the report "ARISE 2" (Advancing Research in Science and Engineering). This report already provides practical recommendations for adapting transdisciplinarity to the structure of higher education as a new discipline. The last Supporting wave was launched in September 2019. The peculiarity of this wave is that it completes the action of all longterm rigid and soft programs of transdisciplinarity development as meta-discipline. Therefore, the meaning, content, and results of real-life events in this seven-year wave, related to the development of transdisciplinarity, as meta-disciplines are predetermined. In this context, the appearance of this article is a predetermined event of a hard program (Basic wave). According to this model it can be assumed that the urgency to solve the multifactorial problems of modern society will contribute to the fact that transdisciplinarity by September 2026 will be adopted in the structure of higher education as a meta-discipline.

\section{CONCLUSIONS}

An analysis of the primary sources - resolutions of international forums, reports, and articles shows the following. Firstly, the Dunning-Kruger effect (Kruger \& Dunning, 1999) can significantly limit the efficiency and effectiveness of the transdisciplinary team of specialists from different disciplines. Their observations suggest an increase in the risk of erroneous conclusions and unsuccessful decisions in the work of such a team. The existence of such a risk can have negative consequences for the solution of multifactorial problems of science, nature, and society. Secondly, it is necessary to keep in mind that modern science consists of four interrelated elements: fundamental (academic) science, science in the structure of higher education, applied (commercial) science, and bumanistic science (Soete, Schneegans, Eröcal, Angathevar, \& Rasiah, 2015). Within each science element, the level of competence of the team members, the research methods, as well as the assessment of the results and the level of moral responsibility for the consequences of the practical implementation of these results will be determined by the target context. Therefore, within the framework of "transdisciplinarity for science," transdisciplinarity plays the role of a declaration proclaiming the ability to identify and combine methods that best support only the ongoing research. The central element of transdisciplinarity for science is the search for a unique method that can prove its effectiveness in current scientific research. 
In turn, the "transdisciplinarity for education" direction allows presenting transdisciplinary meta-discipline as an educational initiative that prepares and licenses a student for professional practice. Therefore, the central element of transdisciplinarity for education is the formation of a transdisciplinary worldview based on systemic thinking in the framework of standard transdisciplinary departments.

Thus, all of the above allows us to speak about the possibility and necessity to develop an international standard of transdisciplinary education. It also helps us to describe the unified content of transdisciplinary competence for students of various disciplines at all levels of higher education (bachelor's, master's, and postgraduate studies). The unified level of transdisciplinary competence will eliminate the need to find compromises between disciplinary specialists, as well as the need to show a Dunning-Kruger effect in the transdisciplinary team. Since the management of complex social processes and the solution of multifactorial problems will be taken based on the requirements of transdisciplinary meta-discipline, disciplinary specialists within the framework of the transdisciplinary team in any state will have the same level of moral and legal responsibility for the results of organizational and managerial decisions made in research and professional activities.

Therefore, today we can only talk about which university or group of universities, which state or group of states will take the responsibility to begin the seven years of large-scale work on consultations, specialized forums, and the formation of a group of experts. These experts will prepare textbooks and create an international standard of transdisciplinary education and transdisciplinary competence for students of diverse disciplines at all levels of higher education (bachelor's, master's, and post-graduate studies).

\section{REFERENCES}

Akyeampong, D., Margalit, A., d'Ambrosio, U., Nakamura. Y., Berger, R. \& Nicolescu. B. (1986). Declaration of the Symposium "Science and the boundaries of knowledge: The prologue of our cultural past". Venice, 7 March 1986. Retrieved from http://basarab-nicolescu.fr/declaration de venise.php\#en

American Academy of Arts and Sciences. (2013). ARISE II: Unleashing America's research \& innovation enterprise, 14. Retrieved from https://www.amacad.org/multimedia/pdfs/publications/researchpapersmonographs/arise2.pdf

Apostel, L. (1972). Terminology and concepts. Interdisciplinarity: Problems of Teaching and Research in Universities. Paris. OECD Publ, 79-81. Retrieved from https://archive.org/details/ERIC ED061895/page/n77

Aristotle. (335-323 BCE). Сочинения [Works]. Vol 1. (V.F. Asmus, Trans). Moscow, Thought Publ, (1975), 68, 349. (Original work published in 335-323 BCE.). Retrieved from http://padaread.com/?book $=25354 \& p g=1$

Berger, G. (1972). Conditions for defining the problems of interdisciplinarity. Interdisciplinarity: Problems of teaching and research in universities. Paris, OECD Publ, 25-26. Retrieved from https://archive.org/details/ERIC ED061895/page/n23

Berger, R., Cazenave, M., Juarroz, R., Freitas, L. \& Nicolescu, B. (1991). Congrès "Science et tradition: perspectives transdisciplinaires, ouvertures vers le XXIe siècle" [The Congress "Science and tradition: Transdisciplinary perspectives, openings towards the 21st century"]. Paris, UNESCO, 2-6 December 1991. Retrieved from http://basarab-nicolescu.fr/science et tradition.php\#fr

Bertalanffy, L. V. (1968). General system theory: Foundations, development, applications. New York: George Braziller Inc.

Brenner, J. E. (2014). Systems and information: Transdisciplinary study. In B. Nicolescu \& A. Ertas (Eds.), Transdisciplinary education, philosophy, \& applications (pp. 1-31). Lubbock, TX. The Academy of transdisciplinary learning \& Advanced studies the ATLAS Publ. Retrieved from http://www.theatlas.org/index.php?option $=$ com phocadownload\&view $=$ category\&id $=1$ :books\&Itemid $=93$ 
Transdisciplinary Education and Transdisciplinary Competence

Bergmann, M., \& Jahn, T. (2019). Transdisciplinarity as critical transdisciplinarity. [Abstract booklet.] International transdisciplinarity Conference 2019. Joining forces for change, Gothenburg, Sweden 10 - 13 September 2019, 161. Retrieved from http://transdisciplinarity.ch/en/td-net/Veranstaltungen/Vergangene-ITDs/ITD2019.html

Bergmann, M., Jahn, T., Knobloch, T., Krohn, W., Pohl, C., \& Schramm, E. (2012). Methods for transdisciplinary research. Frankfurt, Campus Publ, 15.

Brandt, P., Ernst, A., Gralla, F., Luederitz, C., Lang, D. J., Newig, J., Reinert, F. Abson, D. J., \& Wehrden, H. (2013). A review of transdisciplinary research in sustainability science. Ecological Economics, 92(C), 1-15. https://doi.org/10.1016/j.ecolecon.2013.04.008

Gobeil, M., \& Nicolescu, B. (1997). Le projet CIRET-UNESCO Évolution transdisciplinaire de l'université [The CIRET-UNESCO project Transdisciplinary evolution of the university]. Retrieved from http://ciret-transdisciplinarity.org/projet ciret unesco.php\#fr

Feyerabend, Р. (1986). Избраннызе труды по методалогии науки [Selected works on the methodology of science]. Moscow, Progress Publ, 458.

Fufaev, V.V. (2006). Экономические ченозы организачий [Economic cenosises of organizations]. Moscow, Center for systems research Publ. Retrieved from http://oaocsi.ru/Ценоз-MAKET.pdf

International Transdisciplinarity Conference. (2019). Joining forces for change. Gothenburg, Sweden 10 - 13 September 2019. Retrieved from http://transdisciplinarity.ch/en/td-net/Veranstaltungen/VergangeneITDs/ITD-2019.html

Jahn, T., Bergmann, M., \& Keil, F. (2012). Transdisciplinarity: Between mainstreaming and marginalization. Ecological Economics, 79, 1-10. https://doi.org/10.1016/j.ecolecon.2012.04.017

Jantsch, E. (1970). Inter- and transdisciplinary university: A systems approach to education and innovation. Policy Sciences, 1, 403-428. https://doi.org/10.1007/BF00145222

Jantsch, E. (1972). Towards interdisciplinarity and transdisciplinarity in education and innovation. Interdisciplinarity: Problems of teaching and research in universities. Paris. OECD Publ, 99, 105-106. Retrieved from https://archive.org/details/ERIC ED061895/page/n101

Judge, E. (1994). Transdisplinarity-3 as the emergence of patterned experience, part I. Contribution to the 1 st World congress of transdisciplinarity. Arrabida, Portugal, November 1994. Retrieved from http://www.laetusinpraesens.org/docs/tranpat1.php

Kasa, S., \& Pohl, C. (2019). Methods for transdisciplinarity and how to use them. [Abstract booklet.] International transdisciplinarity conference 2019. Joining forces for change. Gothenburg, Sweden $10-13$ September 2019, 106. Retrieved from http://transdisciplinarity.ch/en/td-net/Veranstaltungen/Vergangene-ITDs/ITD2019.html

Kim, Y. (1998). Transdisciplinarity. Stimulating synergies, integrating knowledge. UNESCO, Division of Philosophy and Ethics, 38. Retrieved from http://unesdoc.unesco.org/images/0011/001146/114694eo.pdf

Kruger, J. \& Dunning, D. (1999). Unskilled and unaware of it: How difficulties in recognizing one's own incompetence lead to inflated self-assessments. Journal of Personality and Social Psychology, 77(6), 1121-1134. https://doi.org/10.1037//0022-3514.77.6.1121

Kueffer, C., Hadorn, G. H., Bammer, G., Kerkhoff, L. V. \& Pohl, C. (2007). Towards a publication culture in transdisciplinary research. GALA - Ecological Perspectives for Science and Society,16(1), 22-26. https://doi.org/10.14512/gaia.16.1.8

Laszlo, E. (1995). Problems and prospects of transdisciplinary unified theory. In E. Laszlo, The interconnected universe: Conceptual foundations of transdisciplinary unified theory (pp. 137-141). Singapore and London: World scientific. https://doi.org/10.1142/9789814261401_0010

Lattuca, L. R. (2001). Creating interdisciplinarity: Interdisciplinary research and teacbing among college and university faculty. Nashville. Vanderbilt University Press. 
Lotrecchiano, G. R. \& Misra, S. (2018). Transdisciplinary knowledge producing teams: Toward a complex systems perspective. Informing Science: the International Journal of an Emerging Transdiscipline, 21, 51-74. https://doi.org/10.28945/4086

Mello, M. (2001). Transdisciplinarity: An experience in implementation. São Paulo: Center for transdisciplinary education (CETRANS). University of São Paulo. Retrieved from http:// ciret-transdisciplinarity.org/bulletin/b16c12.php

Mokiy, V. S. (2019a). Systems transdisciplinary approach in the general classification of scientific approaches. European Scientific Journal, 15(19), 247-258. https://doi.org/10.19044/esj.2019.v15n19p247

Mokiy, V. S. (2019b). Training generalists in higher education: Its theoretical basis and prospects. Informing Science: the International Journal of an Emerging Transdiscipline, 22, 55-72. https://doi.org/10.28945/4431

Mokiy, V. S., \& Lukianova, T. А. (2016). От Аисциплинарности к трансдисциплинарности в понятиях и определениях [From disciplinarity to transdisciplinarity in concepts and definitions]. Universum: Social Sciences, 7(25). Retrieved from http://7universum.com/ru/social/archive/item/3435

Mokiy, V. S., \& Lukianova, T. A. (2019). The external and internal planet's limits to growth: Transdisciplinary rethinking. International Journal of Humanities and Social Science, 9(9), 134-144. https://doi.org/10.30845/ijhss.v9n9a16

Morin, E. (1999). La Tête bien faite. Repenser la réforme, réformer la pensée [Reform of thinking. Rethinking reform, reforming thinking]. Paris: Editions du Seuil.

Morin, Е. (2005). Метод. Природа природзг [Method. Nature of nature]. Moscow: Progress-Tradition Publ.

Nicolescu, B. (1987). Moral project. Paris: The International center for transdisciplinary research (CIRET). Retrieved from http://ciret-transdisciplinarity.org/moral project.php

Nicolescu, B. (1994). The charter of transdisciplinarity. The interdisciplinary encyclopedia of religion and science. Retrieved from http://inters.org/Freitas-Morin-Nicolescu-Transdisciplinarity

Nicolescu, B. (2006). Transdisciplinarity - Past, present and future. In B. Haverkort \& C. Reijntjes (Eds.), Moving Worldviens - Reshaping sciences, policies and practices for endogenous sustainable development (pp. 142-166). Holland: COMPAS Editions. Retrieved from http://basarab-nicolescu.fr/Docs articles/Worldviews2006.htm\# ftn1

Nowotny, H., Scott, P. \& Gibbons, M. (2001). Retbinking science: Knowledge and the public in an age of uncertainty. Cambridge, England: Polity Press.

Piaget, J. (1972). The epistemology of interdisciplinary relationships. Interdisciplinarity: Problems of teacbing and research in universities. Paris. OECD Publ. Retrieved from https://archive.org/details/ERIC ED061895/page/n135

Rimondi, G., \& Veronese, M. (2018). Defining the dialogue between sciences: A view on transdisciplinary perspective in the human sciences. Informing Science: the International Journal of an Emerging Transdiscipline, 21, 255268. https://doi.org/10.28945/4115

Soete, L., Schneegans, S., Eröcal, D., Angathevar, B., \& Rasiah, R. (2015). UNESCO science report: Towards 2030 - Executive summary. UNESCO Digital Library. Retrieved from https://unesdoc.unesco.org/ark:/48223/pf0000235407

Volckmann, R. (2007) Transdisciplinarity: Basarab Nicolescu talks with Russ Volckmann. Integral Review, 4(2007), 73-90. Retrieved from https://integral-review.org/transdisciplinarity-basarab-nicolescu-talkswith-russ-volckmann/

World Declaration on Higher Education for the Twenty-First Century: Vision and Action. (1998). UNESCO, World conference on higher education. Paris, 5-9 October 1998. Retrieved from http://www.unesco.org/education/educprog/wche/principal/declar.html 


\section{BIOGRAPHY}

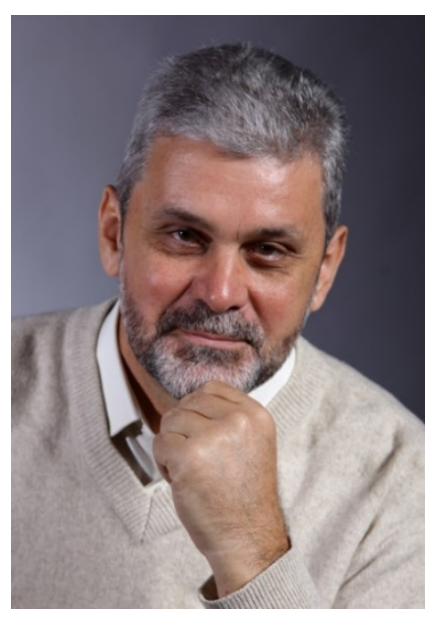

Dr. Vladimir Mokiy is the Head of the Russian School of Transdisciplinarity (http://td-science.ru); Head of the Scientific Research Laboratory of Transdisciplinary Planning and Forecasting in Kabardino-Balkarsky State University, Russia (from 1996 to 2003); Director of Institute of Transdisciplinary Technologies, Russia (from 2007 to present); Member of the Russian Philosophical Society (from 2015 to present); Member of the Society of Architects of Russia (from 2013 to present); Member of the International Academy of Organizational Sciences, Russia (from 2016 to present); and Member of the Research Group Systems Science and Philosophy of the Bertalanffy Center for the Study of Systems Science (BCSSS), Austria (from 2017 to present). A complete bibliography of Dr. Vladimir Mokiy can be found by following this link: http://td-science.ru/index.php/kabinet-direktora/26-eng/473-curricu$\underline{\text { lum-vitae }}$ 